\title{
Histopathological Changes and Tissue Residue Deposition in Broiler Birds Following Profenofos Administration
}

\author{
A. Kafle ${ }^{1 *}$, D.C. Roy ${ }^{1}$, J. Sarma ${ }^{1}$, T.N. Upadhyaya ${ }^{2}$, J.D. Mahanta ${ }^{3}$ and R. Gogoi ${ }^{4}$ \\ ${ }^{1}$ Department of Pharmacology and Toxicology, ${ }^{2}$ Department of Veterinary Pathology, \\ ${ }^{3}$ Department of Poultry Science, ${ }^{4}$ Department of Pharmacology and Toxicology, College of \\ Veterinary Science, A.A.U., Khanapara, Guwahati-781022, Assam, India \\ *Corresponding author
}

\section{A B S T R A C T}

\section{Keywords}

Profenofos, Acute,

Histopathology,

Broiler

Article Info

Accepted:

04 December 2017

Available Online:

10 January 2018
To study the Histopathological changes and tissue residue deposition in broiler birds following profenofos administration. Twenty birds were divided into two groups, 10 in each group. Group I served as control and group II was treated with single oral dose of Profenofos (16 mg/kg). Representative pieces of tissues from liver, kidney, lung, brain and muscle were collected for histopathological examination and residue estimation. Birds treated with profenofos showed marked histopathological changes. Cellular swelling, coagulative necrosis, hydropic degeneration and congestion were observed in most of the tissue examined. The brain section revealed neuronophagia and setellosis. The concentration of profenofos residues ranged from 0.02 to $0.05 \mathrm{ug} / \mathrm{g}$ in tested tissues. The level of residue in tissue was found to be maximum in brain while least was observed in muscle. Profenofos administration at the dose of $16 \mathrm{mg} / \mathrm{kg}$ cause considerable histopathological changes and little tissue residue deposition.

\section{Introduction}

Organophosphates are widely used in agriculture to control crop pests and in livestock to control ectoparasites (Nolan and Roberson, 1979). Profenofos is popular name in the family of organophosphate insecticide which is used in both agriculture and nonagriculture practices. It particularly inhibits the enzyme cholinesterase which results in accumulation of Acetylcholine and hence signs of parasympathetic stimulation. Assam is mainly an agriculture based state, where pesticides are widely used by the farmers. The average use pattern of chemical pesticides was estimated to be $11.5 \mathrm{~kg} / \mathrm{ha}$ in the Assam valley (Gurusubramanian et al., 2008). The Maximum Residue Limit (MRL) of Profenofos in various organs and tissue in chicken is $0.05 \mathrm{ug} / \mathrm{g}$ (Table of MRL for agriculture chemicals). Profenofos is used in large scale to control pests on maize crops the latter is fed to the broiler birds as maize crushed so there is a high risk of introducing profenofos in food chain. Keeping in view the present study was conducted to evaluate the pathological effect of acute exposure to Profenofos in broiler chickens. Also the 
residue was estimated for the sake of public health importance.

\section{Materials and Methods}

\section{Animals}

A total of 25 unsexed day old chicks, procured from Poultry corner, Khanapara Guwahati 781022 were wing banded, weighed, and reared in Instructional Poultry Farm (IPF), CVSc, Khanapara. The birds were housed in deep litter system, with ad libitum supply of feed and water. The experimental trials were approved by the Institutional Animal Ethics Committee (No.770/ac/CPCSEA/FVSc/ AAU/IAEC/15-16/356).

\section{Chemical}

Profenofos 50\% EC, procured from Plant remedies, Hazipur, India was used for this study.

\section{Experimental protocol}

The birds were divided into two group consisting of 10 birds each. The birds were kept in the farm for 7 days for acclimatisation and then fasted overnight prior to experiment. Group I served as control which were fed with distilled water p.o. once orally with gavage neddle. Profenofos was administered to birds of group II @ $16 \mathrm{mg} / \mathrm{kg}$ i.e., LD 50 dose which was obtained after conducting pilot study. Fresh preparation was administered orally once p.o. Doses were calculated on body weight basis and administered accordingly. The birds were closely watched for the presence of clinical signs, if any. Within 4 hours of profenofos administration $40 \%$ of the birds in group II showed marked signs of parasympathetic overstimulation and finally died. The rest were sacrificed at the end of 36 hours and the tissues were collected separately for both histopathological and tissue residue study as per the standard protocol.

\section{Histopathological study}

Representative samples of the liver, kidney, brain and lungs were collected in $10 \%$ formal saline. After washing in running water and dehydration in alcohol, tissues were embedded in liquid paraffin, and $5 \mu \mathrm{m}$ paraffin sections cut and stained with hematoxylin and eosin as per standard method. [Luna, 1968]

\section{Tissue residue study}

Liver, kidney, brain and muscle tissue samples were collected fresh during post mortem examination of dead and sacrificed bird in both the treatment groups (Group I and Group II) in sterile sample containers. About 1 gram of chicken tissues viz. liver, kidney, muscle and brain were cut into small pieces and transferred to a $250 \mathrm{ml}$ conical flask. $100 \mathrm{ml}$ HPLC grade acetonitrile was added to it. The sample was then sonicated, centrifuged, filtered and passed through C18 cartridges. The elute is then finally filtered using syringe filter. Chromeleon (version 6.8) software was used for quantification of the samples. HPLC analysis was done as per the standard method (Rao et al., 2003).

\section{Statistical analysis}

The data were expressed as mean \pm standard error. The statistical significance of the mean differences between control and treated groups was analyzed by one way ANOVA using SPSS 16.0. The level of significance was set at $P<0.05$.

\section{Results and Discussion}

Birds in test group (group II) started showing clinical signs like depression (Fig. 1), ruffled 
feather, hurdling, hypersalivation, drooling (Fig. 2), diarrhoea (Fig. 3) and incordination (Fig. 4), within 3 hours of profenofos administration. The signs in some birds further progressed to convulsion and finally death, while the rest managed to survive. Histopathological alterations in the liver were characterized by congestion, haemorrhages with vacuolar degeneration of hepatocytes, and focal mononuclear cells infiltration (Fig. 1). The kidney section showed degenerative changes of the tubular epithelium characterized by cellular swelling and mild vacuolar degeneration (Fig. 2). There were focal areas of coagulative necrosis while some tubules also showed hydropic degeneration. Congestion of the alveolar capillaries with focal areas of pneumonia and marked cellular obliteration in the underlying parenchyma were evident in the lung histopathology (Fig. 3 ). The histopathological changes observed in brain sections of acute toxicity group were neuronal degeneration, satellitosis and neuronophagia in the cerebrum (Fig. 4).

The concentration of profenofos residues ranged from 0.02 to $0.05 \mathrm{ug} / \mathrm{g}$ in the tissue tested (Table 1).

Table.1 Profenofos residue in various tissues

\begin{tabular}{c|c|c|c|c|}
$\begin{array}{c}\text { Amount of } \\
\text { Profenofos } \\
(\boldsymbol{\mu g} / \mathrm{g})\end{array}$ & \multicolumn{3}{|c|}{ ACUTE TOXICITY (GROUP II) } \\
\hline $\mathbf{N = 1 0 .}$ & Brain & Liver & Kidney & Muscle \\
\hline & $0.052 \pm 0.01$ & $0.023 \pm 0.01$ & $0.029 \pm 0.01$ & $0.02 \pm 0.01$ \\
\hline
\end{tabular}

Fig.1 Bird showing sign of depression

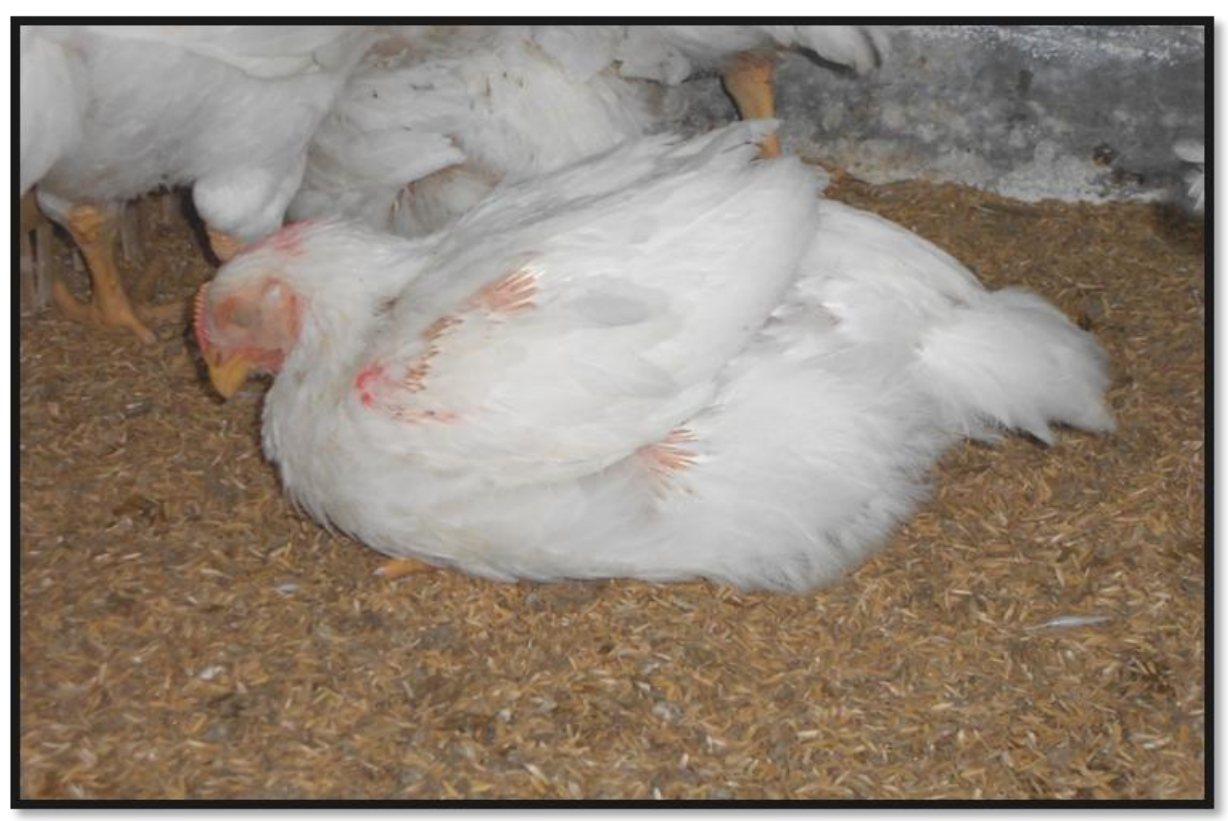


Int.J.Curr.Microbiol.App.Sci (2018) 7(1): 206-213

Fig.2 Bird showing drooling of saliva

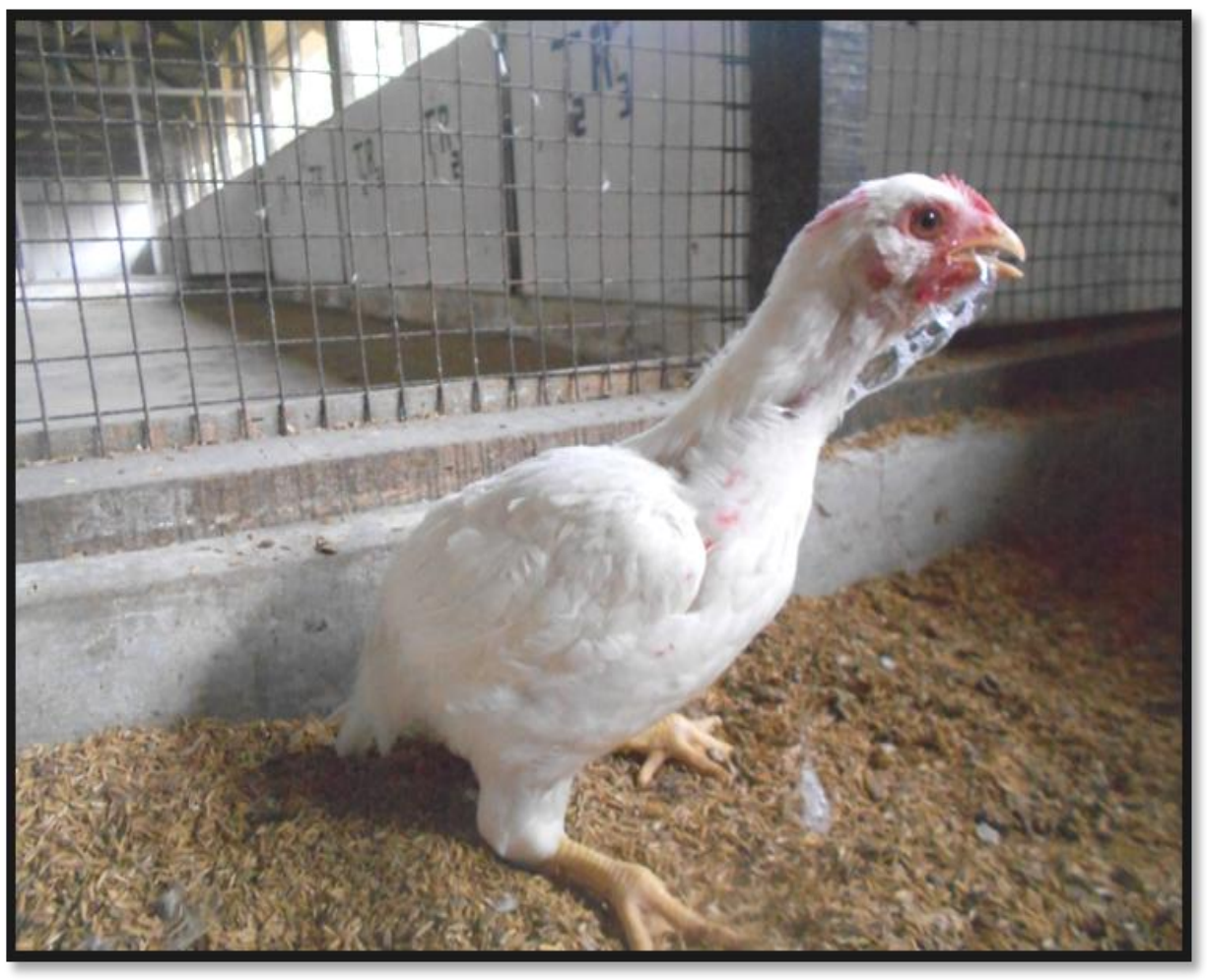

Fig.3 Bird showing diarrhoea

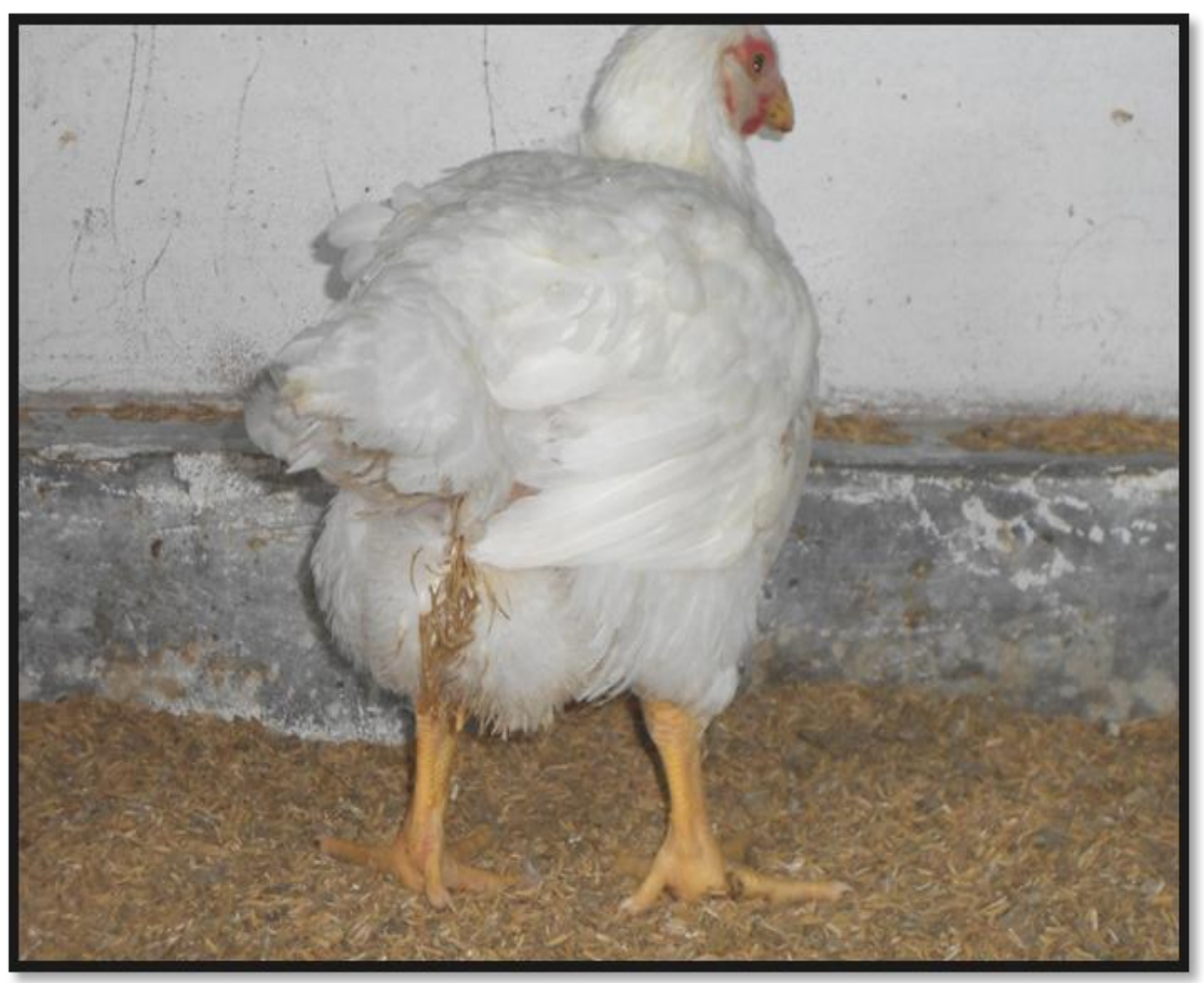


Int.J.Curr.Microbiol.App.Sci (2018) 7(1): 206-213

Fig.4 Bird showing incordination

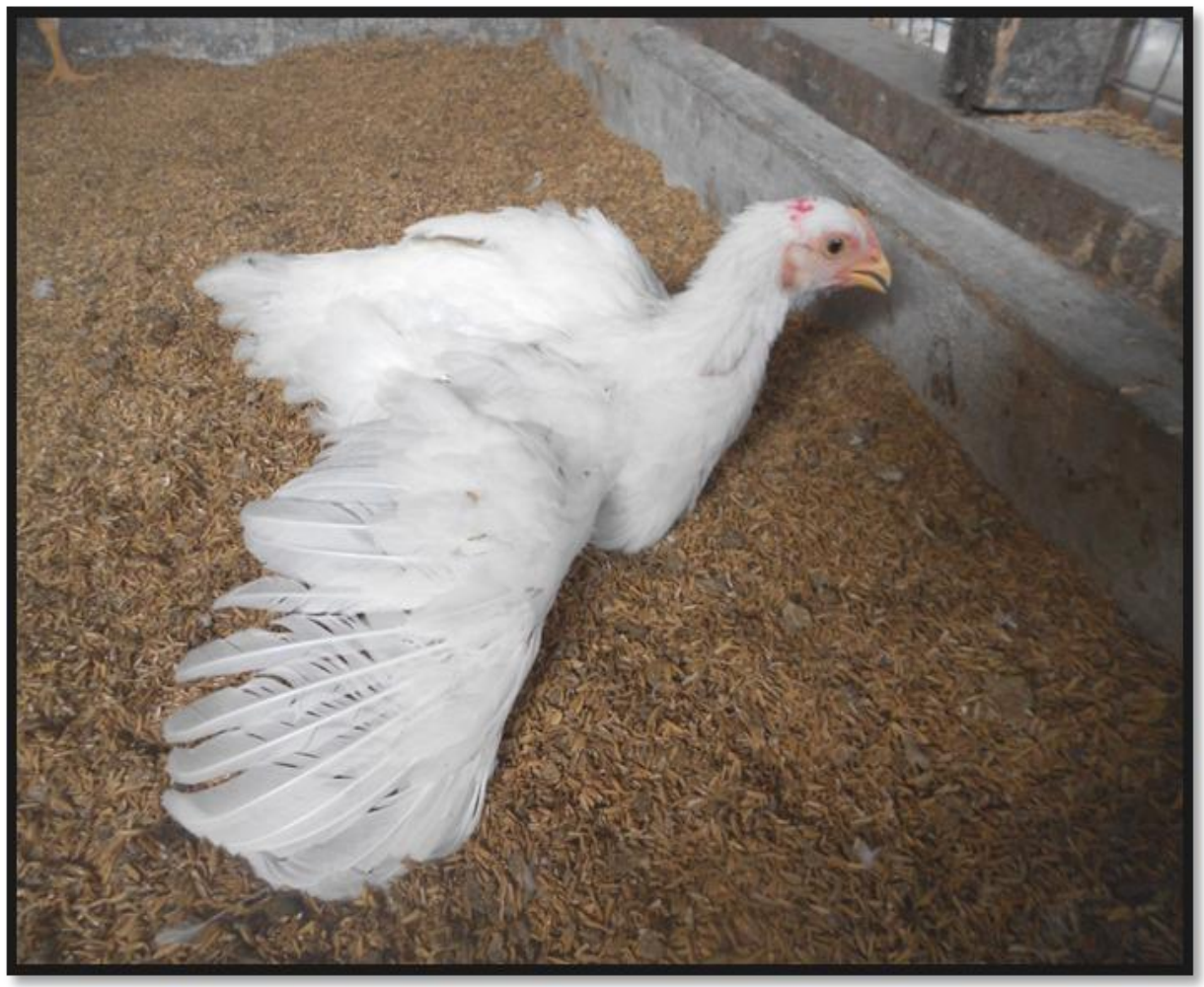

Fig.5 Photomicrograph of liver showing congestion and infiltration of inflammatory cells ( $\mathrm{H}$ and E, ×400) (group II)

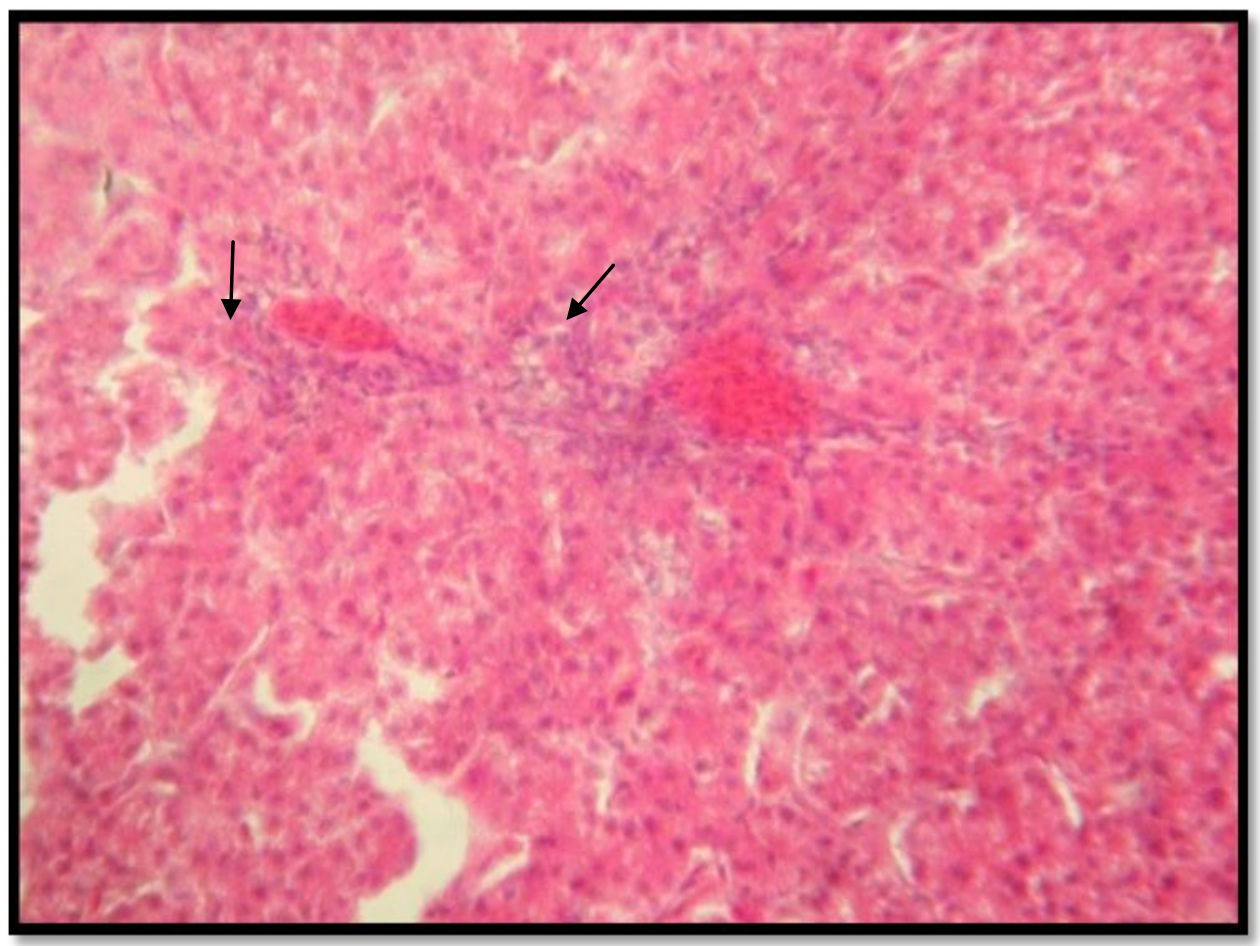


Fig.6 Photomicrograph of kidney showing degeneration and necrosed tubules $(\mathrm{H}$ and $\mathrm{E}, \times 400)$ (group II)

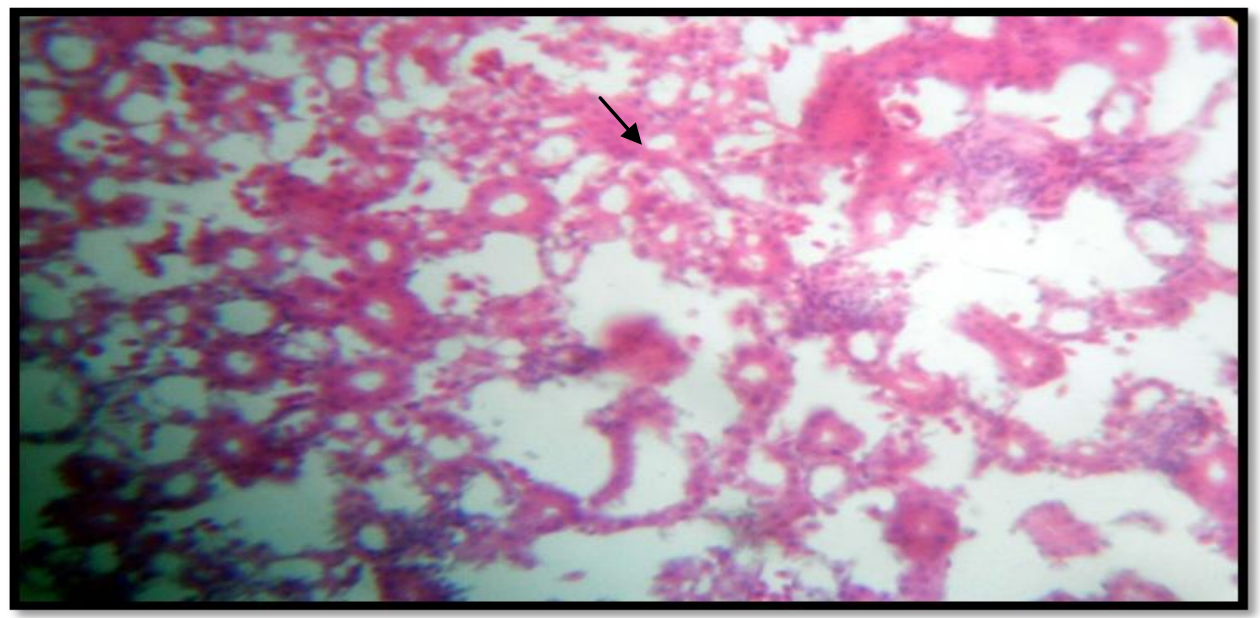

Fig.7 Photomicrograph of lung showing mild congestion (H and E, ×400) (group II)

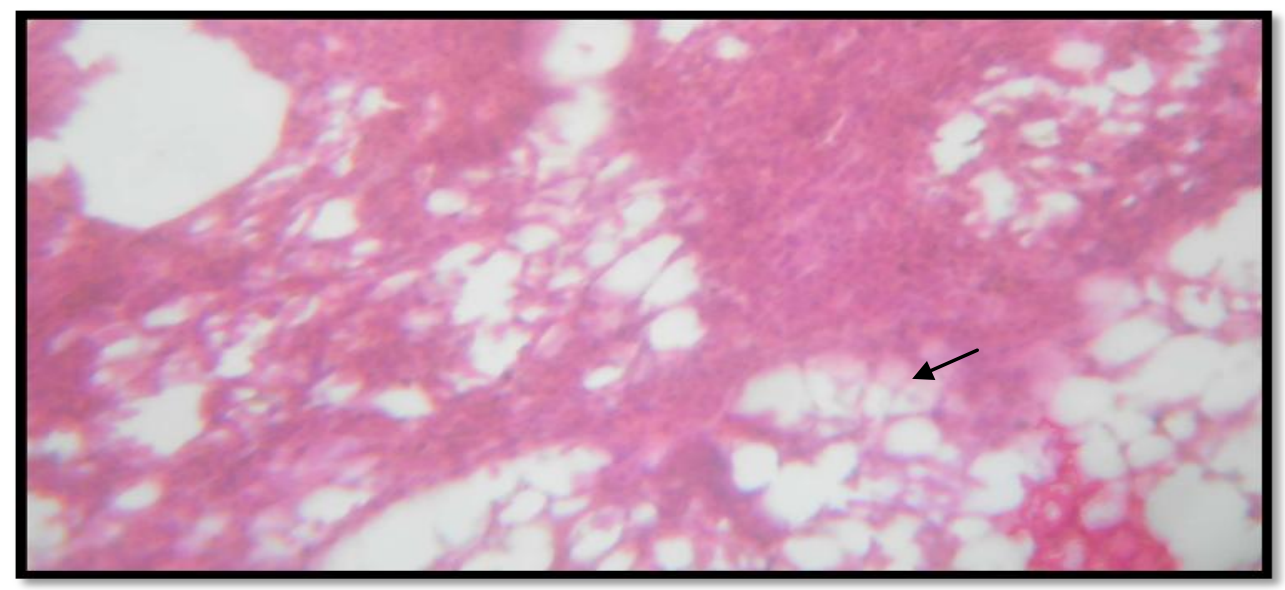

Fig.8 Photomicrograph of brain showing neuronophagia and satellosis (H and E, 400) (group II)

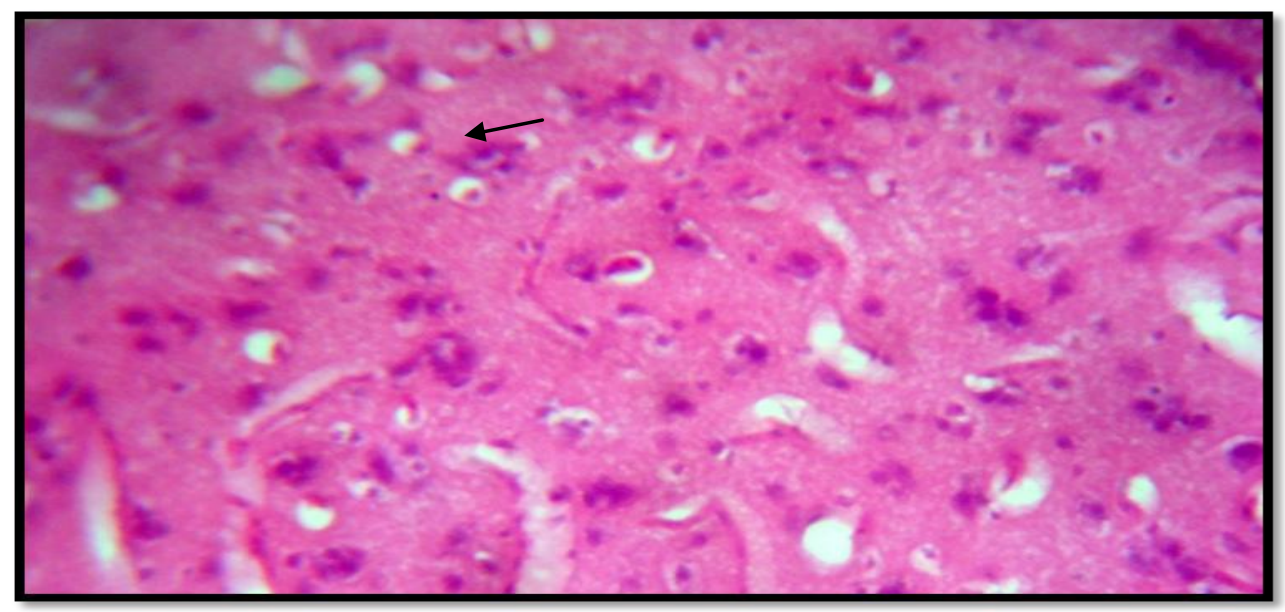


Signs of toxicity appeared within 4 hours of profenofos administration which might be due to its high lipid solubility. The effected birds revealed severe toxicity signs like hypersalivation, tremor, convulsion etc which is the true indicative of cholinergic overstimulation. Trembling, decreased movement and diarrhoea were observed in the animals exposed to pesticides (Najafi et al., 2010). The test compound is found to inhibit cholinesterase enzyme resulting in accumulation of acetylcholine. This buildup of neurotransmitter at the nerve ending results in signs of intoxication includes restlessness, hyper excitability, tremors, convulsions and paralysis (Stevens and Breckenridge). The histopathological alterations mentioned in liver, kidney, lung and brain tissue might be attributed to the toxic effect of profenofos. Liver, being the major organ for biotransformation affected the most which might be due to the irritant nature of the compound. Lesions in the kidneys were indicative of nephrotoxicity of the test compound and its metabolites as kidneys are the major route for elimination for most of the OP compound (Kammon et al., 2010). The residue detected in brain tissue was maximum $(0.05 \mathrm{ug} / \mathrm{g})$ which is the MRL. This can be attributed to the lipid nature of the affected tissue. Residue observed in the present study is in agreement with several workers (Manal et al., 2008; Khalid et al., 2015).

From the present study it can be concluded that although the toxic effect of profenofos had been observed but the dose used was sufficiently high $\left(\mathrm{LD}_{50}\right)$ hence public health education is needed to raise general awareness about hazards of irrational use of Profenofos in agricultural fields.

\section{Acknowledgement}

The author feels indebted to ICAR and Dean, College of Veterinary Science, Assam
Agricultural University, Khanapara for financial help and providing necessary facilities to carry out the research work

\section{References}

Gurusubramanian G, Rahman A, Sarmah M., Ray, S, Bora S. Pesticide usage pattern in tea ecosystem, their retrospects and alternative measures J. Environ. Biol., 2008; 29: 813-826.

Kammon AM, Brar RS, Banga HS, Sodhi S. Pathobiochemical studies on hepatotoxicity and nephrotoxicity on exposure to chlorpyrifos and imidacloprid in layer chickens. Vet. Arh., 2010; 80: 663-72.

Khalid MS, Abdel-Gawad H, Ramzy E, Nagy M. Harmful impact of profenofos on the physiological parameters in Nile tilapia, Oreochromis niloticus. Int. J. Ba. App. Sci., 2015; 4 :19-26.

Luna LG. 3rd ed. London: McGraw-Hill; 1968. Manual of Histologic Staining Methods of the Armed Forces Institute of Pathology.

Manal M, Yehya M, Yousef M. Pathological and Biochemical Studies of Profenofos toxicity on Rats. Egypt. J. Comp. Path. Path., 2008; 21: 75-92.

Najafi G, Razi M, Hoshyar A, Shahmohamadloo S, Feyzi S. The effect of chronic exposure with imidacloprid insecticide on fertility in mature male rats. Int. J. Fert. Sterility, 2010; 4: 9-16.

Nolan MP, Roberson E.L. Veterinary Pharmacology and Therapeutics. Oxford and IBH Publication, Co.; New Delhi 1979; Pp. 1107-1111.

Rao RN, Raju DN, Venkateswarlu N, Rao BV, Parvathi N, Majula A, et al., Journal of Chromatographic Science 2003; 41: 418-421.

Stevens JT and Breckenridge CB. Crop Protection Chemicals. In: Principles and Methods of Toxicology. 4th edn; Edited 
by: Wallace, Taylor \& Francis, Philadelphia, pp. 565648.

Table of MRL for agriculture chemicals. The Japan Food Chemical Research
Foundation. Available online at: http//http://www.m5.ws001.squarestart. ne.jp/foundation/agrdtl.php?a_inq $=6670$ 0 .

\section{How to cite this article:}

Kafle, A., D.C. Roy, J. Sarma, T.N. Upadhyaya, J.D. Mahanta and Gogoi, R. 2018. Histopathological Changes and Tissue Residue Deposition in Broiler Birds Following Profenofos Administration. Int.J.Curr.Microbiol.App.Sci. 7(01): 206-213. doi: https://doi.org/10.20546/ijcmas.2018.701.023 